\title{
Calcium-dependent fusion of the plasma membrane fraction from human neutrophils with liposomes
}

\author{
Joseph W. Francis, James E. Smolen, Kenneth J. Balazovich, Rebecca R. Sandborg \\ and Laurence A. Boxer \\ Division of Hematology / Oncology, Department of Pediatrics, The University of Michigan School of Medicine, Ann Arbor, MI (U.S.A.)
}

(Received 8 January 1990)

Key words: Neutrophil; Liposome; Membrane fusion; Erythrocyte; Calcium ion dependence

A cell-free assay monitoring lipid mixing was used to investigate the role of $\mathrm{Ca}^{2+}$ in neutrophil membrane-liposome fusion. Micromolar concentrations of $\mathrm{Ca}^{2+}$ were found to directly stimulate fusion of inside-out neutrophil plasma membrane enriched fractions (from neutrophils subjected to nitrogen cavitation) with liposomes (phosphatidylethanolamine: phosphatidic acid, 4:1 molar ratio). In contrast, right-side-out plasma membranes and granule membranes did not fuse with liposomes in the presence of $\mathrm{Ca}^{2+}$. Similar results were obtained with two different lipid mixing assays. Fusion of the neutrophil plasma membrane-enriched fraction with liposomes was dependent upon the concentration of $\mathrm{Ca}^{2+}$, with threshold and $50 \%$ maximal rate of fusion occurring at $2 \mu \mathrm{M}$ and $50 \mu \mathrm{M}$, respectively. Furthermore, the fusion was highly specific for $\mathrm{Ca}^{2+}$; other divalent cations such as $\mathrm{Ba}^{2+}, \mathrm{Mg}^{2+}$ and $\mathrm{Sr}^{2+}$ promoted fusion only at millimolar concentrations. Red blood cell (RBC) membranes were used in control studies. $\mathrm{Ca}^{2+}$-dependent fusion did not occur between right-side-out or inside-out RBC-vesicles and liposomes. However, if the RBC-vesicles were exposed to conditions which depleted spectrin (i.e., low salt), then $\mathrm{Ca}^{2+}$-dependent fusion was detected. Other quantitative differences between neutrophil and RBC membranes were found; fusion of liposomes with RBC membranes was most readily achieved with $\mathrm{La}^{3+}$ while neutrophil membrane-liposome fusion was most readily obtained with $\mathrm{Ca}^{2+}$. Furthermore, GTP $\gamma \mathrm{S}$ was found to enhance $\mathrm{Ca}^{2+}$-dependent fusion between liposomes and neutrophil plasma membranes, but not RBC membranes. These studies show that plasma membranes (enriched fractions) from neutrophils are readily capable of fusing with artificial lipid membranes in the presence of micromolar concentrations of $\mathrm{Ca}^{2+}$.

\section{Introduction}

Membrane fusion is fundamentally important to neutrophil antimicrobial function. During cell activation, intracellular granules fuse with the plasma membrane, resulting in the release of toxic granule products [1], formation of phagolysosomes and insertion of proteins into the plasma membrane [2]. Although the conditions and stimuli required for neutrophil activation and exo-

Abbreviations: PE, phosphatidylethanolamine; PA, phosphatidic acid; R18, octadecyl rhodamine; RhPE, $N$-(lissamine rhodamine B sulfonyl)PE; NBDPE, $N$-(7-nitrobenz-2-oxa-1,3-diazol-4-yl)PE; EDTA, ethylenediaminetetraacetic acid; EGTA, ethyleneglycol bis $\beta$ aminoethyl ether)- $N, N, N^{\prime}, N^{\prime}$-tetraacetic acid; FMLP, $N$-formylmethionylleucylphenylalanine; PMSF, phenylmethylsulfonyl fluoride; EDAC, 1-ethyl-3-(3-dimethylaminopropyl)carbodiimide-HCl; RBC, red blood cell.

Correspondence: J.W. Francis, Department of Pediatrics, Room 7500 MSRB I, Box 0684, University of Michigan, Ann Arbor, MI 48109, U.S.A. cytosis have been well characterized [3], relatively little is known about the mechanism of granule-plasma membrane fusion.

A variety of intracellular mediators such as fatty acids and divalent cations have been suggested to participate in membrane fusion during degranulation of secretory cells. $\mathrm{Ca}^{2+}$ has been implicated since it promotes fusion of liposomes and isolated cellular membranes in vitro [4-6] and, in general, intracellular $\mathrm{Ca}^{2+}$ levels are increased during activation of exocytic cells [7-12]. Recent studies have shown that $\mathrm{Ca}^{2+}$ is mobilized from intracellular stores during neutrophil activation, and degranulation is both $\mathrm{Ca}^{2+}$-dependent [13] and paralleled by a rise in free intracellular $\mathrm{Ca}^{2+}[14]$. However, these studies utilized either intact or permeabilized cells and thus the direct involvement of $\mathrm{Ca}^{2+}$ in neutrophil membrane fusion has not yet been demonstrated.

Neutrophils are good sources of membranes that are involved in exocytosis because granule and inside-out plasma membrane fractions have been characterized and can be readily isolated by nitrogen cavitation and 
density-gradient centrifugation $[15,16]$. We employed fluorescent lipid-mixing techniques to detect fusion between liposomes and both plasma membrane- and granule membrane-enriched fractions. Liposomes were used because they could be efficiently labeled with fluorescent lipid probes and have been shown to fuse with neutrophil granules in the presence of millimolar concentrations of $\mathrm{Ca}^{2+}$ [17]. In this study, we used two independent assays to quantitate lipid-mixing: probe dilution and resonance energy transfer. Our results show that micromolar concentrations of $\mathrm{Ca}^{2+}$ directly promoted the fusion of liposomes with neutrophil plasma membranes (enriched in inside-out vesicles). The granule-enriched membrane fractions did not fuse with liposomes or with plasma membrane-enriched fractions under the same conditions. These results suggest that $\mathrm{Ca}^{2+}$ may promote or enhance neutrophil membrane fusion by direct interaction with membrane components.

\section{Methods}

\section{Materials}

Phosphatidylethanolamine (PE), phosphatidic acid (PA), and phosphatidylserine (PS) were purchased from Avanti Polar Lipids (Birmingham, AL) and Sigma Chemical Co. (St. Louis, MO). Octadecyl rhodamine (R18), $N$-(lissamine rhodamine B sulfonyl) PE (RhPE), and $N$-(7-nitrobenz-2-oxa-1,3-diazol-4-yl)-PE (NBDPE) were purchased from Molecular Probes (Eugene, OR). Chloroform, $\mathrm{LaCl}_{3}$ and $\mathrm{SrCl}_{2}$ were obtained from Fisher Scientific (Fairlawn, NJ). Ethylenediaminetetraacetic acid (EDTA), ethyleneglycol bis( $\beta$-aminoethyl ether)$N, N, N^{\prime}, N^{\prime}$-tetraacetic acid (EGTA), $\mathrm{NaCl}, \mathrm{KCl}$, $\mathrm{BaCl}_{2}, \mathrm{CaCl}_{2}$, Hepes, dithiothreitol (DTT), $N$-formylmethionylleucylphenylalanine (FMLP) and $\mathrm{MgCl}_{2}$ were obtained from Sigma. Phenylmethylsulfonylfluoride (PMSF) was purchased from United States Biochemical (Cleveland, $\mathrm{OH}$ ). Polybed 812 and uranyl acetate were purchased from Polysciences (Warrington, PA). Concanavalin A-colloidal gold was purchased from E.Y. Laboratories (San Mateo, CA). Aminoalkylagarose (Affi-Gel 102) and 1-ethyl-3-(3-dimethylaminopropyl)carbodiimide- $\mathrm{HCl}$ (EDAC) were purchased from BioRad Laboratories (Richmond, CA).

\section{Liposomes}

Mixtures of PE/PA (4:1, molar ratio) or PE/PS ( $4: 1$, molar ratio) in chloroform were dried under a steady stream of argon in a high vacuum for $1 \mathrm{~h}$. The resulting lipid films were hydrated in a solution of 130 $\mathrm{mM} \mathrm{KCl}, 5 \mathrm{mM} \mathrm{NaCl}, 10 \mathrm{mM}$ Hepes (KCl-Hepes) and $0.1 \mathrm{mM}$ EDTA or $1 \mathrm{mM}$ EGTA and treated for $2 \mathrm{~min}$ in a water bath sonicator followed by $30 \mathrm{~s}$ with a micro-probe sonicator (Fisher). This procedure resulted in predominantly small unilamellar vesicles as de- termined by electron microscopy. R18, NBDPE or RhPE were incorporated into some liposome preparations by adding them to the phospholipid/chloroform mixture; R18, NBDPE, RhPE comprised approx. 2\% of the total phospholipid concentration. R18, NBDPE or RhPE which were not incorporated into vesicles were removed by gel filtration using Sephadex G-75 (Pharmacia) and a solution of $130 \mathrm{mM} \mathrm{KCl}, 5 \mathrm{mM} \mathrm{NaCl}, 10 \mathrm{mM}$ Hepes and $0.1 \mathrm{mM}$ EDTA.

\section{Neutrophil isolation and cavitation}

Whole blood from healthy adult donors was collected by venipuncture into heparinized syringes. Neutrophils were isolated by density centrifugation on $\mathrm{Hy}-$ paque-Ficoll gradients [18] followed by dextran sedimentation [19]. Residual erythrocytes were removed by hypotonic lysis [19]. Neutrophils were washed by centrifugation in phosphate-buffered saline (PBS) and suspended in cavitation buffer consisting of $0.34 \mathrm{M}$ sucrose, $0.1 \mathrm{mM} \mathrm{MgCl}_{2}, 1 \mathrm{mM}$ EDTA, $1 \mathrm{mM}$ DTT, $10 \mathrm{mM}$ Hepes, and $1 \mathrm{mM}$ PMSF (pH 7.4). Neutrophils ((50$100) \cdot 10^{6} / \mathrm{ml}$ ) were subjected to nitrogen cavitation using a method similar to that described by Jesaitis et al. [20]. Briefly, the cells were subjected to nitrogen at $375 \mathrm{psi}$ for $20 \mathrm{~min}$ at $4^{\circ} \mathrm{C}$ in a cell disruption chamber (Parr Inst., Moline, IL). The cavitate was collected dropwise and first centrifuged at $1000 \times \mathrm{g}$ for $5 \mathrm{~min}$ to remove intact cells and nuclei and then at $10000 \times g$ for $10 \mathrm{~min}$. The granule-enriched fraction (pellet) was resuspended in 1-2 $\mathrm{ml}$ of $\mathrm{KCl}-\mathrm{Hepes}$ buffer. The supernatant was centrifuged at $100000 \times \mathrm{g}$ for $60 \mathrm{~min}$; the resulting pellet was defined as the plasma membraneenriched fraction. The plasma membrane-enriched fraction was resuspended in $1 \mathrm{ml}$ of $\mathrm{KCl}$-Hepes buffer to a concentration of approx. $0.5-1.0 \mathrm{mg}$ protein $/ \mathrm{ml}$. The final supernatant was defined as the cytosolic fraction. Some cavitates were separated on discontinuous percoll gradients. Azurophil granule $(\alpha)$, specific granule $(\beta)$, and plasma membrane $(\gamma)$ enriched fractions were harvested as described [21]. Residual percoll was removed from these fractions by centrifugation at 100000 $\times g$ for $90 \mathrm{~min}$.

\section{Preparation of red blood cell vesicles}

Red blood cells (RBC) were collected by dextran sedimentation during leukocyte isolation. The RBCs were washed three times in $5 \mathrm{mM} \mathrm{Na}{ }_{2} \mathrm{HPO}_{4}, 150 \mathrm{mM}$ $\mathrm{NaCl}$ (pH 8.0). The washed $\mathrm{RBCs}$ were lysed in $5 \mathrm{mM}$ $\mathrm{Na}_{2} \mathrm{HPO}_{4}, 5 \mathrm{mM}$ PMSF and centrifuged at $40000 \times g$ for $10 \mathrm{~min}$. The resulting $\mathrm{RBC}$ ghosts were suspended in $5 \mathrm{mM} \mathrm{Na}{ }_{2} \mathrm{HPO}_{4}, 5 \mathrm{mM}$ PMSF and washed. This procedure was repeated 5-7 times. The RBC ghosts were inverted by centrifuging them twice in $0.3 \mathrm{mM}$ $\mathrm{Na}_{2} \mathrm{HPO}_{4}$ (pH 7.6). Some inside-out $\mathrm{RBC}$ vesicles were exposed to conditions which strip spectrin and other proteins from the membrane [22]. Stripping was accom- 
plished by incubating them at $37^{\circ} \mathrm{C}$ for $30 \mathrm{~min}$ with agitation in $0.3 \mathrm{mM} \mathrm{Na}{ }_{2} \mathrm{HPO}_{4}$ and washing them by centrifugation at $40000 \times \mathrm{g}$ for $20 \mathrm{~min}$. Right-side-out vesicles were prepared by including $1 \mathrm{mM} \mathrm{MgSO}_{4}$ in the $5 \mathrm{mM} \mathrm{Na}_{2} \mathrm{HPO}_{4}$ buffer. The RBC-vesicle preparations were stored at $4^{\circ} \mathrm{C}$ until they were used.

\section{Characterization of membrane vesicle orientation and size} by electron microscopy

Membrane vesicles were applied to 200-mesh, formvar-coated copper grids and negatively stained using a $5 \%(w / v)$ methanolic solution of uranyl acetate. Preparations of liposomes were predominantly comprised of small unilamellar ( $>85 \%$ of the total vesicle population) and multilamellar structures having a mean diameter of $0.05 \pm 0.01 \mu \mathrm{m}$. Preparations of inside-out RBC vesicles were homogeneous and had a mean vesicle diameter of $0.8 \pm 0.2 \mu \mathrm{m}$. The neutrophil plasma membrane-enriched fraction was heterogeneous with respect to membrane vesicle density and mean diameter $(0.7 \pm$ $0.5 \mu \mathrm{m}$, range $0.15-2.0 \mu \mathrm{m})$. Neutrophil plasma membrane-enriched fractions prepared by nitrogen cavitation were composed of membrane vesicles having both a natural orientation (i.e., right-side-out) and an inside-out orientation. To determine the orientation of vesicles in this subcellular fraction, vesicles were incubated with concanavalin A-colloidal gold (Con A-gold) at 4.2 $\mu \mathrm{g} / \mathrm{ml}$ in $\mathrm{KCl}$-Hepes buffer for 12 hours at $4^{\circ} \mathrm{C}$. Vesicles were washed free of unbound reagent using two rounds of centrifugation and fixed with $2.5 \%$ glutaraldehyde in $0.1 \mathrm{M}$ sodium cacodylate buffer ( $\mathrm{pH}$ 7.4). Vesicles were post-fixed with $1.0 \% \mathrm{OsO}_{4}$, dehydrated through a graded ethanol series, and embedded in Polybed 812. Ultra-thin sections of this material were counter-stained with uranyl acetate and lead citrate. To control for non-specific Con A-gold binding some samples were treated exactly as described but with the addition of a 100-fold excess concentration of Con A. Photomicrographs of Con A-gold-labeled membranes (three samples from two separate experiments) were enlarged to a uniform $64500 \times$ magnification. Membranes observed on micrographs were scored for Con A-gold label; membranes were defined as labeled if they had $\geq 2$ gold particles located within one particle diameter (i.e., $15 \mathrm{~nm}$ ) of their membrane. Only those vesicles having a complete and clearly demarcated unit membrane were scored (total vesicles scored, 1492). All electron microscope observations were made using a Phillips 400 microscope operating at $60 \mathrm{kV}$.

\section{Isolation of inside-out oriented plasma membrane vesicles by density gradient centrifugation}

Inside-out oriented plasma membrane vesicles were enriched by using ligand induced density perturbation to selectively deplete right-side-out vesicles [23]. Ligand induced density perturbation was achieved by incubat- ing crude plasma membrane preparation with Con Agold $(4.2 \mu \mathrm{g} / \mathrm{ml})$ for $60 \mathrm{~min}$ at $4{ }^{\circ} \mathrm{C}$ followed by density gradient centrifugation $(82000 \times \mathrm{g}, 30 \mathrm{~min})$ on a discontinuous sucrose gradient $(15,35$, and $60 \%)$. The inside-out enriched membrane vesicles were harvested from the 15/35\% sucrose interface. To determine the percentage of inside-out vesicles, the membranes were washed at $100000 \times g$ to remove sucrose and subjected to sialic acid analysis according to the method of Steck and Kant [24].

\section{Lipid mixing-fusion assays}

Relief of R18 self-quenching. Lipid mixing was assayed by quantitating increased rhodamine fluorescence due to the relief of self-quenching of R18 in fusing membranes, using a Perkin-Elmer 650-10S spectrofluorimeter. R18-labeled liposomes, granules, or plasma membrane-enriched fractions were stirred with unlabeled liposomes or granules at $37^{\circ} \mathrm{C}$. Fusion was induced by adding various combinations of divalent cations. Free $\mathrm{Ca}^{2+}$ concentrations were determined for the $\mathrm{KCl}-\mathrm{Hepes}$ buffer by ion-selective electrodes [25]. All fluorescence signals were expressed as a percentage of relative maximum fluorescence, obtained by adding $0.1 \%$ Triton X-100 to lipid mixtures. The phospholipid ratio of R18-labeled to unlabeled vesicles or liposomes as $1: 5$ for all assays.

NBDPE-RhPE resonance energy transfer. RhPE was incorporated into the plasma membrane or granule membrane-enriched fractions by incubating an ethanolic solution of the probe with the membranes for $30 \mathrm{~min}$ at room temperature. The final ethanol concentration was $<1 \%$. Unincorporated rhodamine was removed by gel filtration on Sephadex G-75. RhPE-labeled liposomes or membrane enriched fractions were added to NBDPE labeled-liposomes. Lipid mixing of NBDPE labeled membranes with RhPE-labeled membranes results in energy transfer from NBD to rhodamine and a subsequent increase in rhodamine fluorescence intensity at $595 \mathrm{~nm}(\mathrm{Ex}=460 \mathrm{~nm})[6,26]$.

Rhodamine $(E x=560 \mathrm{~nm}, E m=610 \mathrm{~nm})$ and NBD $(E x=460 \mathrm{~nm}, E m=530 \mathrm{~nm})$ were monitored using a Perkin-Elmer 650-10S spectrofluorimeter equipped with a temperature-regulated-cell holder and magnetic stirring device. In some experiments, fluorescence and right-angle-light-scatter were monitored simultaneously by using two emission channels in a SLM fluorimeter (SLM/AMINCO). Phospholipid concentrations were determined by the phosphate assay of Morrison [27]. Protein was assayed using the Bio-Rad procedure.

\section{FMLP-affinity chromatography}

FMLP-affinity chromatography was used to characterize the sidedness of plasma membranes according to the method of Ochs and Reed [28] except that Affi-Gel 102 was used in place of agarose-hexylamine. Briefly, 
FMLP $(200 \mu \mathrm{M})$ was conjugated to $5 \mathrm{ml}$ Affi-Gel 102 using EDAC $\left(36 \mathrm{mg} / 30 \mathrm{ml} \mathrm{H}_{2} \mathrm{O}\right)$ at $\mathrm{pH} 4.5$ for $10 \mathrm{~h}$. The column was washed with $50 \mathrm{ml} \mathrm{H}_{2} \mathrm{O}$ followed by $100 \mathrm{ml} \mathrm{KCl}$-Hepes buffer. Non-specific binding was diminished by first adding bovine serum albumin (10 $\mathrm{mg} / \mathrm{ml}$ ) to the column and washing it with $200 \mathrm{ml}$ of $\mathrm{KCl}$-Hepes buffer. The plasma membrane fraction was added to the column at $0.5 \mathrm{mg} / \mathrm{ml}$; the bound fraction was eluted with FMLP $(10 \mathrm{mg} / \mathrm{ml})$.

\section{Results}

Preparation and characterization of inside-out plasma membrane-enriched vesicles

The isolated membrane fractions in our preparations were composed of vesicles, as observed by electron microscopy (not shown). We were interested in the proportions of inside-out plasma membrane vesicles present in these preparations since orientation is likely to be crucial to fusion events in vitro. The percentages of inside-out and right-side-out oriented vesicles were evaluated by, (1) counting the vesicles that bound Con A-gold, (2) analyzing the fractions binding FITC-Con A following FMLP-affinity chromatography and, (3) sialic acid analysis. The data from these techniques revealed that the percentage of inside-out vesicles varied with each membrane preparation, but fell within a range of $40-60 \%$ of the total.

Inside-out plasma membrane vesicles were enriched by Con A-gold-induced density perturbation (as described in Methods). Enrichment of inside-out vesicles in our preparations was determined by analyzing the percentage of right-side-out plasma membrane vesicles depleted during this procedure. Plasma membrane enriched fractions were incubated with or without Con A-gold and separated by centrifugation on sucrose gradients. In the non-Con A-gold-labeled membrane preparation, greater than $90 \%$ of the total neuraminidase-cleavable sialic acid (in the presence of Triton $\mathrm{X}-100,0.1 \%$ ) was found at the $15 / 35 \%$ sucrose interface. For the vesicles harvested at this interface, $60 \pm$ $24 \%$ of the sialic acid was accessible to neuraminidase before the addition of Triton X-100, suggesting that this proportion of the membranes were right-side-out and intact. In the membrane preparation density-shifted with Con A-gold only $34 \pm 17 \%$ of the sialic acid residues were accessible to neuraminidase cleavage, apparently by depletion of right-side-out vesicles. Thus inside-out plasma membrane vesicles could be consistently enriched to a level of $69-89 \%(n=4)$.

Use of probe dilution lipid-mixing to assess fusion of neutrophil plasma membrane-enriched fractions with granule-enriched fractions or phospholipid vesicles

Neutrophil plasma membrane or granule fractions were labeled with octadecyl rhodamine (R18) and stirred

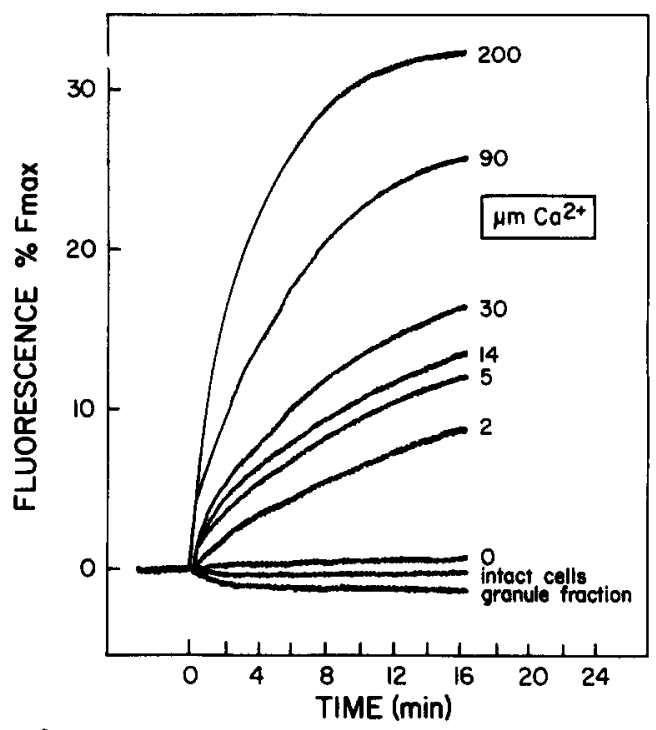

Fig. 1. $\mathrm{Ca}^{2+}$-dependent fusion of liposomes with the inside-out enriched neutrophil plasma membrane fraction. Membrane-enriched fractions from nitrogen-cavitated neutrophils $(50 \mu \mathrm{M})$ were mixed with R18-labeled liposomes $(10 \mu \mathrm{M})$ at $37^{\circ} \mathrm{C}$ in $\mathrm{KCl}$-Hepes buffer with $1 \mathrm{mM}$ EGTA. $\mathrm{Ca}^{2+}$ caused a dose-dependent increase in rhodamine fluorescence due to fusion of inside-out enriched plasma membrane fractions with R18-labeled liposomes. $\mathrm{Ca}^{2+}$-dependent fusion was not detected between liposomes and the granule enriched fractions or intact cells. Representative experiment; $n=5$.

in a cuvette at $37^{\circ} \mathrm{C}$ with either unlabeled granule or plasma membrane-enriched fractions. Fusion was assessed as the relief of self-quenching of R18 [29]. Lipid mixing was not detected between granule or inside-out plasma membrane enriched fractions in the presence of $\mathrm{Ca}^{2+}(1-1000 \mu \mathrm{M})$. Over extended periods of time (5-60 min) a slow, continuous, spontaneous increase in rhodamine fluorescence was observed (not shown). However, $\mathrm{Ca}^{2+}$ at best only minimally enhanced the increase in rhodamine fluorescence.

The inability of the neutrophil fractions to fuse in a $\mathrm{Ca}^{2+}$-dependent manner may be due to inactivity of one or both membrane fractions. To test this hypothesis, we analyzed the interactions of either granule or plasma membrane-enriched fractions with liposomes which were known to be sensitive to $\mathrm{Ca}^{2+}$-dependent fusion [30]. The liposomes employed were labeled with R18 and composed of phosphatidylethanolamine and phosphatidic acid (PE:PA, 4:1). The R18-labeled liposomes fused with unlabeled liposomes (PE:PA, $4: 1$ ), but required millimolar concentrations of $\mathrm{Ca}^{2+}$ and $\mathrm{Mg}^{2+}$ (not shown). The R18-liposomes also fused in a $\mathrm{Ca}^{2+}$ dependent manner with inside-out eirriched neutrophil plasma membrane fractions but not with granules or intact cells (Fig. 1). In addition, sucrose fractions containing density shifted right-side-out vesicles (which were washed free of sucrose) did not fuse with R18-liposomes (not shown). Only micromolar concentrations of $\mathrm{Ca}^{2+}$, were required to obtain fusion; $\mathrm{Mg}^{2+}$ was inac- 
tive at these concentrations. Furthermore, crude plasma membrane fractions isolated by centrifugation in $\mathrm{KCl}-$ Hepes $\left(6 \cdot 10^{6} \mathrm{~g} \cdot \mathrm{min}\right)$ or enriched membrane fractions isolated by density gradient centrifugation on sucrose or percoll gradients were all found to fuse in a $\mathrm{Ca}^{2+}$-dependent manner with the liposomes. Corresponding granule fractions, including enriched azurophil or specific granule fractions (from percoll gradients), were inactive in this system.

Since the observed fluorescence changes could conceivably be caused by cation-dependent detergent effects, osmotic swelling or lipid phase transitions, R18liposomes or R18-neutrophil membranes were each exposed to $\mathrm{Ca}^{2+}$ and $\mathrm{Mg}^{2+}$ in the absence of unlabeled vesicles or neutrophil membrane fractions. No fluorescence intensity changes could be detected. Furthermore, changes in right-angle-light-scattering (which would increase the fluorescence signal) did not contribute to the fluorescence intensity (not shown).

Calcium requirements of neutrophil plasma membrane fraction-liposome fusion

The threshold concentrations of $\mathrm{Ca}^{2+}$ required to detect lipid mixing was $2 \mu \mathrm{M}$ (Fig. 1), although in some experiments lipid mixing could be detected as low as 1 $\mu \mathrm{M} . \mathrm{Ca}^{2+}$-dependent fusion was most sensitive to micromolar concentrations of $\mathrm{Ca}^{2+}$, with the half-maximal initial rate of fusion occurring at $50 \mu \mathrm{M}$ (Fig. 2). The fluorescence signal due to lipid mixing was biphasic, with a rapid initial rate of fusion and a subsequent slow continuous increase (Fig. 1). The rapid initial rate of fusion was dramatically decreased or eliminated if the plasma membrane-enriched fraction was sonicated prior to its combination with the liposomes (not shown). The fusion reaction was also dependent on the concentration of plasma membrane-enriched fraction; approx. $10^{7}$ cell equivalents of the plasma membrane-enriched

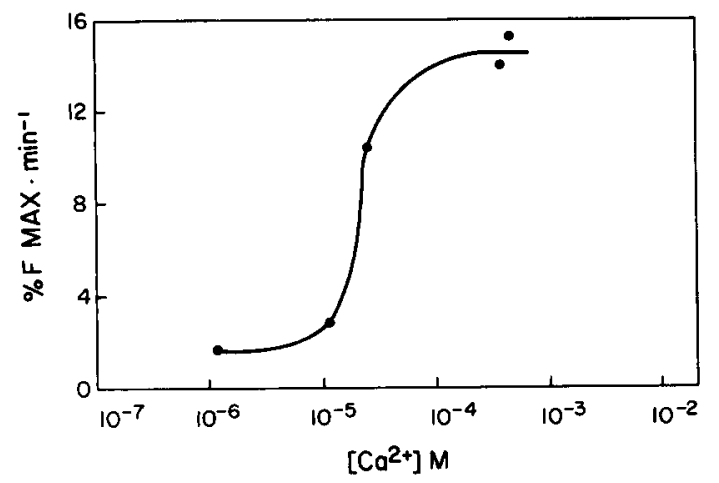

Fig. 2. $\mathrm{Ca}^{2+}$-concentration dependence of neutrophil plasma membrane-liposome fusion. Conditions were similar to those described in Fig. 1. The data are expressed as $\%$ maximal rate of fusion per min which is calculated from the initial rate of fusion at $10 \%$ of maximal fluorescence. Representative experiment; $n=5$.

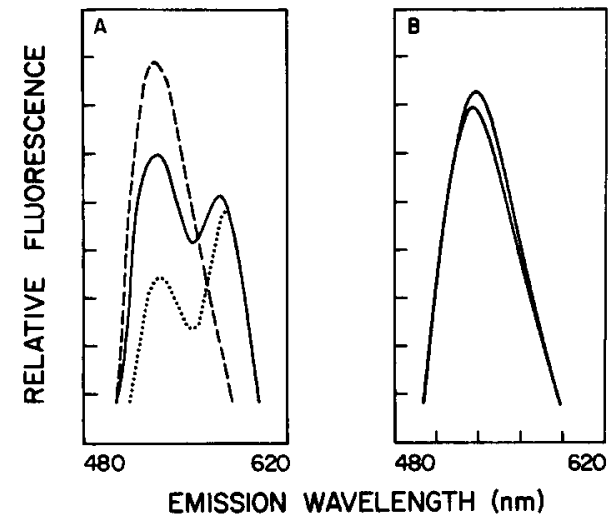

Fig. 3. Detection of $\mathrm{Ca}^{2+}$-dependent fusion of the plasma membrane enriched fraction of neutrophils with liposomes using an energy transfer assay. NBDPE-labeled liposomes $(10 \mu \mathrm{M})$ were mixed with RhPE-labeled neutrophil plasma membrane $(40 \mu \mathrm{M})$ at $37^{\circ} \mathrm{C}$ in $\mathrm{KCl}-\mathrm{Hepes}$ buffer with $1 \mathrm{mM}$ EGTA. The excitation wavelength was set at $460 \mathrm{~nm}$; slit width $5 \mathrm{~nm}$. Addition of $200 \mu \mathrm{M} \mathrm{Ca}^{2+}$ (free $\mathrm{Ca}^{2+}$ concentration) decreased NBD fluorescence and increased rhodamine fluorescence due to energy transfer during plasma membrane-liposome fusion $(-)$ as compared to fluorescence emission before addition of $\mathrm{Ca}^{2+}(---)$. Addition of EDTA $(1 \mathrm{mM})$ following $\mathrm{Ca}^{2+}$ is also shown $(\cdots \cdots)$. Energy transfer was not detected when $\mathrm{Ca}^{2+}$ was added to mixtures of RhPE-labeled granule membranes and NBD-labeled liposomes (B).

fraction (50 $\mu \mathrm{M}$ of lipid) were required for fusion to occur with the liposomes $(10 \mu \mathrm{M})$.

Fusion of neutrophil plasma membranes with liposomes assayed using energy transfer

The $\mathrm{Ca}^{2+}$-dependent fusion of neutrophil membrane-enriched fractions and liposomes was confirmed by another lipid mixing assay. In this assay, lipid-mixing (fusion) was defined as the decrease in NBD-fluorescence with a concomitant increase in rhodamine fluorescence as resonance energy transfer from NBDPE to RhPE occurred in fusing (co-labeled) membranes [6,31]. Changes in fluorescence consistent with energy transfer were detected when micromolar concentrations of $\mathrm{Ca}^{2+}$ were added to mixtures of RhPE-labeled neutrophil plasma membrane-enriched fraction and NBDPElabeled liposomes (Fig. 3). However, no energy transfer was detected between RhPE labeled granule-enriched fractions and NBD-labeled liposomes (Fig. 3). $\mathrm{Ca}^{2+}$ did not induce changes in the fluorescence spectra of separate solutions of NBD-liposomes of the RhPE-plasma membrane fractions. Since this assay may also be sensitive to the aggregation of vesicles [32], EDTA was added to mixtures of fusing membranes. Previous studies have shown that the energy transfer-induced fluorescence intensity changes due to $\mathrm{Ca}^{2+}$-dependent aggregation could be reversed upon the addition of EDTA [32]. Addition of EDTA diminished the NBD fluorescence but did not return it to prestimulatory levels (Fig. 3). This result shows that the energy transfer arose from fusion events rather than aggregation of membrane 
vesicles. The fusion kinetics and $\mathrm{Ca}^{2+}$ dependence observed using the energy transfer technique were similar to the corresponding results obtained with the R18-fluorescence lipid mixing assay (not shown).

\section{Fusion of liposomes with inside-out RBC-vesicles}

Red blood cell (RBC) vesicles were used as another model system to study the $\mathrm{Ca}^{2+}$-dependent fusion of membranes with liposomes. Inside-out and right-sideout $\mathrm{RBC}$ vesicles did not fuse with liposomes. However, if the inside-out $R B C$ vesicles were exposed to $0.3 \mathrm{mM}$ phosphate buffer at $37^{\circ} \mathrm{C}$ for $30 \mathrm{~min}$ fusion with liposomes occurred in a $\mathrm{Ca}^{2+}$-dependent manner (Fig. 4). Exposure of inside-out vesicles to low-molarity phosphate buffer has been shown to deplete spectrin and other proteins from membranes [22]. The total phospholipid and $\mathrm{Ca}^{2+}$ concentrations required to detect fusion were similar to both neutrophil and stripped inside-out RBC plasma membrane. These data confirmed that, in general, $\mathrm{Ca}^{2+}$-induced fusion was specific for inside-out plasma membranes as compared to right-side out membranes.

Promotion of plasma membrane-liposome fusion by $\mathrm{Ba}^{2+}$, $\mathrm{Mg}^{2+}, \mathrm{Sr}^{2+}$, and $\mathrm{La}^{3+}$

Because fusion of neutrophil plasma membrane and RBC-vesicles with liposomes showed similar $\mathrm{Ca}^{2+}$ requirements, their sensitivities to other cations were in-

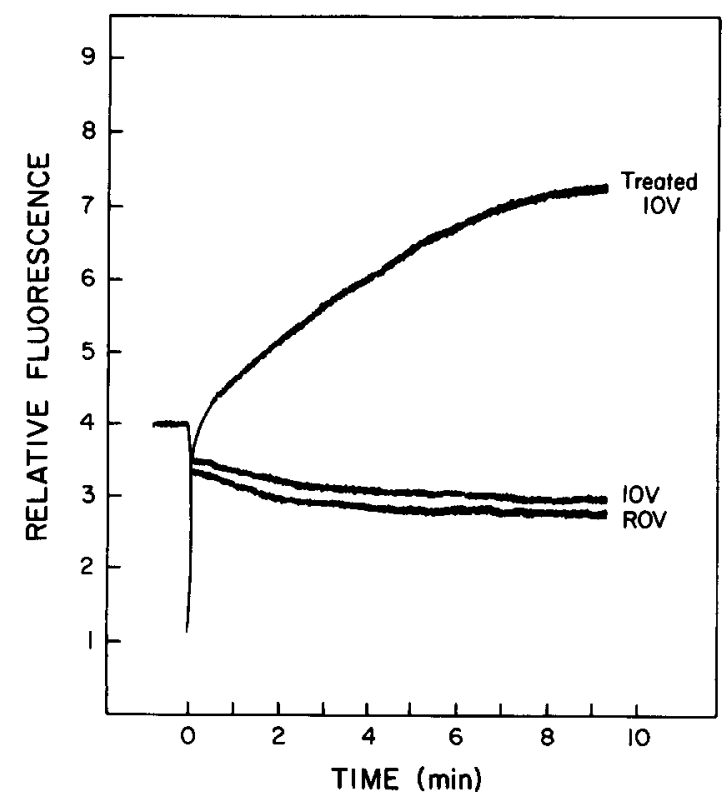

Fig. 4. $\mathrm{Ca}^{2+}$-dependent fusion of inside-out $\mathrm{RBC}$-vesicles with liposomes. RBC-vesicles $(20 \mu \mathrm{M})$ were mixed with R18-labeled liposomes at $37^{\circ} \mathrm{C}$ in $\mathrm{KCl}-\mathrm{Hepes}$ buffer with $1 \mathrm{mM}$ EGTA. $\mathrm{Ca}^{2+}(30 \mu \mathrm{M})$ stimulated fusion of inside-out RBC-vesicles that were exposed to spectrin-depleting conditions (treated-IOV) with liposomes but did not stimulate fusion of inside-out RBC-vesicles not exposed to spectrin/actin depleting conditions (IOV) or right-side out RBC-vesicles (ROV). Representative experiment; $n=3$.

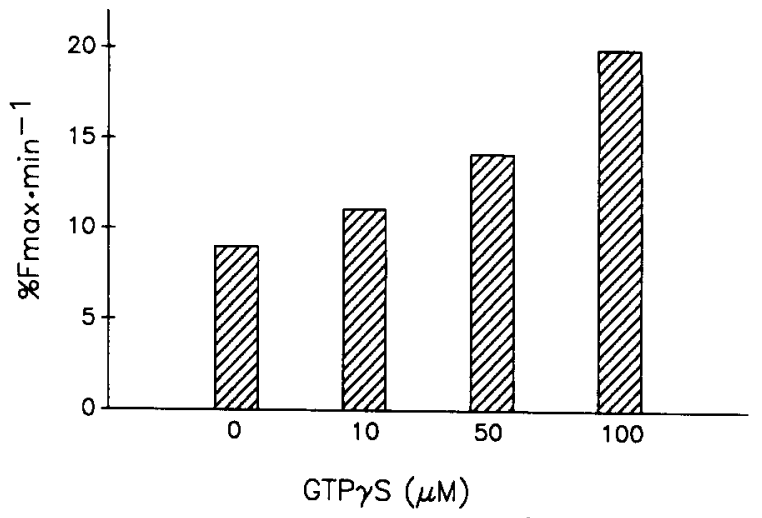

Fig. 5. Enhancement of the initial rate of $\mathrm{Ca}^{2+}$-dependent fusion of inside-out enriched neutrophil plasma membranes and liposomes by GTP $\gamma$ S. The $\mathrm{Ca}^{2+}$ concentration is $30 \mu \mathrm{M}$ for all assays. Plasma membranes $(50 \mu \mathrm{M})$ and liposomes $(10 \mu \mathrm{M})$ are incubated with GTP $\gamma \mathrm{S}$ for $2-5$ minutes at $37^{\circ} \mathrm{C}$, prior to the addition of $\mathrm{Ca}^{2+}$. Representative experiment; $n=3$.

vestigated. Concentrations of cations that elicited halfmaximal initial rates of fusion were recorded. Since the individual liposome preparations varied in their sensitivity to fusion, only a range of concentrations for each cation can be reported. The molar concentrations of each cation required for half-maximal fusion of: (1) neutrophil plasma membrane-enriched fraction with liposomes were:

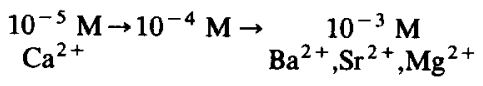

or (2) $\mathrm{RBC}$ vesicle-liposomes were:

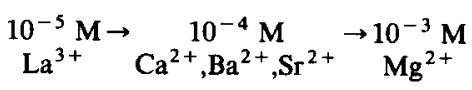

Thus RBC-vesicle liposome fusion was more sensitive to the trivalent cation $\mathrm{La}^{3+}$ than to $\mathrm{Ca}^{2+}$. In comparison, vesicles in the neutrophil plasma membrane-enriched fraction did not fuse with liposomes in the presence of $\mathrm{La}^{3+} \cdot \mathrm{La}^{3+}$ did, however, promote aggregation of vesicles in the neutrophil plasma membrane-enriched fraction, readily observed with the naked eye. Furthermore, micromolar concentrations of $\mathrm{La}^{3+}$ abolished or diminished $\mathrm{Ca}^{2+}$-dependent fusion between neutrophil plasma membrane-enriched fractions and liposomes. This is consistent with reports showing that $\mathrm{La}^{3+}$ is a specific $\mathrm{Ca}^{2+}$ antagonist that can block $\mathrm{Ca}^{2+}$-dependent physiological functions [33,34]. Cations added to R18 liposomes in the absence of unlabeled liposomes did not cause significant changes in fluorescence intensity.

Effect of GTP $\gamma S$ on plasma membrane-liposome fusion $\mathrm{Ca}^{2+}$ may indirectly promote fusion by activating signaling pathways that involve G-proteins. G-proteins can be activated by non-hydrolyzable GTP analogues 


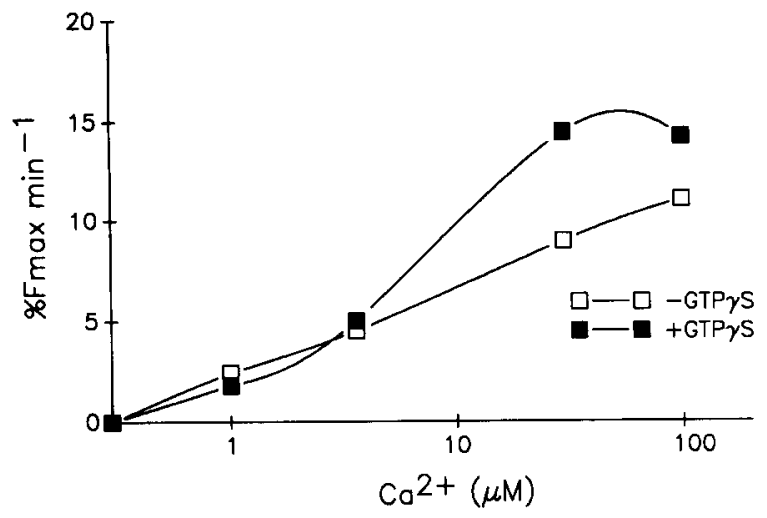

Fig. 6. Effect of GTP $\gamma \mathrm{S}$ on fusion of inside-out enriched neutrophil plasma membrane and liposomes at various concentrations of $\mathrm{Ca}^{2+}$. Conditions are similar to those described in Fig. 5 except that the $\mathrm{Ca}^{2+}$ concentration varies $(1,3.6,30$ and $100 \mu \mathrm{M})$. GTP $\gamma \mathrm{S}$ is at 50 $\mu \mathrm{M}$ for all trials. $\square, \mathrm{GTP} \gamma \mathrm{S}$ pretreatment; $\square$, no GTP $\gamma \mathrm{S}$ pretreatment. Representative experiment; $n=3$.

such as GTP $\gamma$ S. It has been reported that GTP $\gamma \mathrm{S}$ can promote fusion in cell free assays and secretion in permabilized neutrophils $[35,36]$. In our studies GTP $\gamma \mathrm{S}$ alone did not promote fusion between plasma membranes and liposomes. However, GTP $\gamma \mathrm{S}$ enhanced the initial rate of $\mathrm{Ca}^{2+}$-dependent fusion between these components (Fig. 5). GTP $\gamma \mathrm{S}(50 \mu \mathrm{M})$ was found to significantly enhance fusion at $\mathrm{Ca}^{2+}$ concentrations of $30 \mu \mathrm{M}$ or greater, but did not effect (or even diminished) fusion at lower $\mathrm{Ca}^{2+}$ concentrations (Fig. 6). GDP $\beta$ S and GTP $(1-1000 \mu \mathrm{M})$ did not affect $\mathrm{Ca}^{2+}-$ dependent fusion.

GTP $\gamma \mathrm{S}$ only marginally affected $\mathrm{Ca}^{2+}$-dependent fusion between RBC plasma membranes and liposomes at higher GTP $\gamma \mathrm{S}$ concentrations ( $>100 \mu \mathrm{M}$ ). To rule out possible non-specific charge effects of GTP $\gamma \mathrm{S}$ or a fusion promoting contaminant present in the GTP $\gamma S$ preparation, we examined the effect of this nucleotide on fusion between liposomes themselves in the presence of $\mathrm{Ca}^{2+}$; GTP $\gamma \mathrm{S}$ had no effect on this interaction.

\section{Discussion}

$\mathrm{Ca}^{2+}$ has been shown to promote the fusion of liposomes and isolated cellular membranes from a variety of cell types $[4,5,37,38]$. However, the effects of $\mathrm{Ca}^{2+}$ on the fusion properties of isolated neutrophil membranes have not been investigated. In this study, we report that fusion of neutrophil membranes with liposomes is induced by micromolar concentrations of $\mathrm{Ca}^{2+}$. A recent study has shown fusion of neutrophil granule fractions with liposomes (of the same lipid composition used in these studies) using a similar fluorescence lipid mixing technique, Meers et al. [17]. However, arachidonic acid, synexin, and millimolar concentrations of $\mathrm{Ca}^{2+}$ were all required for this system. The fusion of neutrophil plasma membrane-enriched fractions with liposomes that we observed required only the addition of micromolar concentrations of $\mathrm{Ca}^{2+}$. Our findings are consistent with those of Meers et al., since we found that granule-enriched fractions did not readily fuse with liposomes in the presence of micromolar concentrations of $\mathrm{Ca}^{2+}$.

The micromolar concentrations of $\mathrm{Ca}^{2+}$ which were required to stimulate fusion between neutrophil plasma membrane enriched fractions and liposomes were similar to those required for fusion of isolated membrane fractions from other exocytic cell types [38-40]. These other membrane fractions were derived mostly from intracellular organelles such as secretory vesicles [38,41], Golgi [38], and granules [5,40]. Therefore, the fusogenic effects of $\mathrm{Ca}^{2+}$ on isolated plasma membranes has not been extensively examined. Furthermore, investigators who have used isolated plasma membrane fractions in cell-free fusion assays have shown that fusion is ATPdependent and have not emphasized the role of $\mathrm{Ca}^{2+}$ $[42,43]$. The role of $\mathrm{Ca}^{2+}$ in neutrophil exocytic function has been clearly demonstrated $[7,44]$. Accordingly, we found that the threshold concentration of calcium ( 2 $\mu \mathrm{M})$ required to detect fusion between neutrophil plasma membrane-enriched fractions and liposomes falls within the range of the intracellular $\mathrm{Ca}^{2+}$ concentration (1-6 $\mu \mathrm{M})$ detected during neutrophil activation and exocytosis $[45,46]$.

It should also be noted that the concentration of $\mathrm{Ca}^{2+}$ required to promote fusion between neutrophil plasma membranes and liposomes is 100 - to 1000 -fold lower than that required to promote fusion between liposomes. One explanation for the lower $\mathrm{Ca}^{2+}$ requirement could be the association of $\mathrm{Ca}^{2+}$-dependent phospholipid-binding proteins with the plasma membranes. These proteins have been shown to lower the threshold concentration of $\mathrm{Ca}^{2+}$ required for fusion of model membranes [47], cause aggregation of secretory granules [48], and induce secretion in permeabilized cells [49].

Since crude plasma membranes from neutrophils may contain a variety of membrane structures with various orientations, we sought to further define the structure and orientation of the component of the plasma membrane-enriched fraction that was involved in $\mathrm{Ca}^{2+}$-dependent fusion. Electron microscopic analysis showed that the plasma membrane enriched fraction was composed of membrane vesicles, with roughly $50 \%$ of the vesicles in an inside-out orientation. Since the cytoplasmic face of the plasma membrane is involved in fusion, inside-out vesicles would be most relevant to study fusion in a cell free system. We enriched our preparation for inside-out plasma membrane vesicles by selectively depleting right-side out oriented vesicles using lectin induced density perturbation [23]. Inside-out enriched plasma membrane fractions readily fused with liposomes in a $\mathrm{Ca}^{2+}$-dependent manner whereas rightside-out membranes did not. 
RBC plasma membrane vesicles were used as an alternative membrane source to (1) assess the specificity of the $\mathrm{Ca}^{2+}$-dependent neutrophil plasma membrane vesicle-liposome fusion and to (2) compare the $\mathrm{Ca}^{2+}$-dependent fusion of right-side-out versus inside-out plasma membrane vesicles with liposomes. The $\mathrm{Ca}^{2+}$-dependent fusion of inside-out RBC-vesicles with liposomes and the lack of fusion detected with right-side-out RBCvesicles were consistent with our finding that fusion was specific for inside-out plasma membrane vesicles. However, to detect $\mathrm{Ca}^{2+}$-dependent fusion, inside-out $\mathrm{RBC}$ vesicles required exposure to conditions that depleted spectrin and actin, among other proteins [22]. By comparison, the neutrophil plasma membrane did not require additional methods to remove cytoskeletal proteins to become fusogenic. Spectrin has been shown to inhibit $\mathrm{Ca}^{2+}$-dependent fusion of liposomes [50,51] and its deficiency in red cells is associated with membrane deformations due to fusions [52]. Our results are consistent with these reports, but we have extended these observations to show that treatment resulting in spectrin depletion was associated with an increased potential of the inner leaflet of red plasma membranes to fuse in a $\mathrm{Ca}^{2+}$-dependent manner. However, it should be noted that our low salt treatment could have removed other proteins in addition to spectrin which could be involved in modulating fusion.

The following observations indicate that neutrophil plasma membrane-liposome fusion shows greater specificity for physiological concentrations of $\mathrm{Ca}^{2+}$ than certain other cations: (1) millimolar concentrations of $\mathrm{Mg}^{2+}, \mathrm{Ba}^{2+}$ and $\mathrm{Sr}^{2+}$ were required to promote fusion; (2) $\mathrm{La}^{3+}$ decreased $\mathrm{Ca}^{2+}$-dependent fusion. $\mathrm{La}^{3+}$ has been shown to antagonize $\mathrm{Ca}^{2+}$-dependent biological reactions and can displace $\mathrm{Ca}^{2+}$ from $\mathrm{Ca}^{2+}$-binding sites on membranes [34,53]. By comparison, RBC vesicle-liposome fusion showed a greater sensitivity to $\mathrm{La}^{3+}$ than $\mathrm{Ca}^{2+}$. These apparent differences in sensitivity to $\mathrm{La}^{3+}$ between neutrophil plasma membrane enriched fractions and $\mathrm{RBC}$-plasma membrane may be attributed to differences in phospholipid composition or a $\mathrm{La}^{3+}$-binding contaminant in the plasma membrane fraction. Also, it has been shown that $\mathrm{La}^{3+}$ binds to phosphatidylserine [54], a major phospholipid component of the inner leaflet of red cell plasma membranes. It has also been shown that differences in the arrangement and distribution of charged phospholipids may contribute to differences in cation-dependent membrane fusion $[55,56]$.

Since both red cell and neutrophil plasma membranes are sensitive to $\mathrm{Ca}^{2+}$-dependent fusion, we sought to further explore the differences which might exist with these respective membranes. $\mathrm{Ca}^{2+}$ may promote fusion by biophysical and/or biochemical mechanisms, such as dehydration or production of fusogenic fatty acids from enzyme activation, respectively. The $\mathrm{Ca}^{2+}$-depen- dent activation of enzymes may involve G-proteins. G-proteins have been shown to be involved in intracellular fusion events as observed in cell-free assays [57]. Nonhydrolyzable GTP analogues such as GTP $\gamma \mathrm{S}$ have been used to probe G-protein mediated events. It has recently been shown that GTP $\gamma \mathrm{S}$ can enhance $\mathrm{Ca}^{2+}$-dependent secretion in permeabilized neutrophils [58]. Consistent with these observations, we have shown that GTP $\gamma \mathrm{S}$ enhanced $\mathrm{Ca}^{2+}$-dependent fusion of neutrophil plasma membrane-enriched fractions with liposomes but did not readily enhance fusion using red cell plasma membranes. This suggests that fusion of liposomes with RBC plasma membrane did not involve G-proteins and adds support to the hypothesis that fusion in this system occurs predominantly as a result of cation-dependent charge and dehydration effects. However, at least part of the mechanism of fusion using neutrophil membranes may be attributed to activation of G-protein regulated proteins or enzymes. Membrane phospholipases may be good candidates for enzymes involved in neutrophil membrane fusion since they are activated by $\mathrm{Ca}^{2+}$, may be regulated by G-proteins and are involved in the production of fusogenic lipids such as arachidonic acid and diacylglycerols [59].

In summary, we found that $\mathrm{Ca}^{2+}$ can directly promote fusion of inside-out enriched neutrophil plasma membrane fractions with artificial membranes. The apparent lack of $\mathrm{Ca}^{2+}$-dependent fusion of neutrophil granules with membranes suggests that additional conditions and/or cofactors may be required to promote $\mathrm{Ca}^{2+}$-dependent fusion of granules with plasma membranes. This observation is consistent with recent findings that have shown that proteins, fatty acids, nucleotides and phosphorylation reactions may be required for membrane fusion and exocytosis [60-65]. Thus, determining the fusion sensitivity of isolated membrane components to $\mathrm{Ca}^{2+}$ should aid in further elucidation of the cofactor requirements of exocytic membrane fusion in the neutrophil.

\section{Acknowledgments}

This investigation was supported by Research Grants NIH-AI20065 (L.A.B.), NIH-DK 32471 (J.E.S.), NIHAI25641 (K.J.B.) and postdoctoral fellowship (to J.W.F.) NIH-HL07517. We thank Jennie McAlpine for her expert assistance in the preparation of the manuscript.

\section{References}

1 Boxer, L.A. and Smolen, J.E. (1988) in Hematology/Oncology Clinics of North America. Phagocytic Defects I: Abnormalities Outside of the Respiratory Burst (Curnutte, J.T., III, ed.), pp. 101-134, W.B. Saunders, Philadelphia.

2 Petty, H.R., Francis, J.W., Todd, R.F., III and Boxer L.A. (1987) J. Cell. Physiol. 133, 235-242.

3 Sandborg, R.R. and Smolen, J.E. (1988) Lab. Invest. 59, 300-320. 
4 Wilschut, J., Düzgüneş, N. and Papahadjopoulos, D. (1981) Biochemistry 20, 3126-3133.

5 Bental, M., Lelkes, P.I., Scholma, J., Hoekstra, D. and Wilschut, J. (1984) Biochim. Biophys. Acta 774, 296-300.

6 Morris, S.J. and Bradley, D. (1984) Biochemistry 23, 4642-4650.

7 Smolen, J.E. and Stoehr, S.J. (1985) J. Immunol. 134, 1859-1865.

8 Neher, E. (1988) J. Physiol. (Lond.) 395, 193-214.

9 Howell, T.W., Cockcroft, S. and Gomperts, B.D. (1987) J. Cell Biol. 105, 191-197.

10 Knight, D.E. (1987) Biosci. Rep. 7, 355-367.

11 Wollheim, C.B., Ullrich, S., Meda, P. and Vallar, L. (1987) Biosci. Rep. 7, 443-454.

12 Penner, R. and Neher, E. (1988) FEBS Lett. 226, 307-313.

13 Lew, P.D., Monod, A., Waldvogel, F.A., Dewald, B., Baggiolini, M. and Pozzan, T. (1986) J. Cell Biol. 102, 2197-2204.

14 White, J.R., Naccache, P.H., Molski, T.F.P., Borgeat, P. and Sha'afi, R.I. (1983) Biochim. Biophys. Res. Commun. 113, 44-50.

15 Borregaard, N., Heiple, J.M., Simons, E.R. and Clark, R.A. (1983) J. Cell Biol. 97, 52-61.

16 Del Buono, B.J., Luscinskas, F.W. and Simons, E.R. (1989) J. Cell. Physiol. 141, 636-644.

17 Meers, P., Ernst, J.D., Düzgüneş, N., Hong, K.L., Fedor, J., Goldstein, I.M. and Papahadjopoulos, D. (1987) J. Biol. Chem. $262,7850-7858$.

18 Boyum, A. (1968) Scand. J. Clin. Lab. Invest. 21, 77-89.

19 Zurier, R.B., Hoffstein, S. and Weissmann, G. (1973) Proc. Natl. Acad. Sci. USA 70, 844-848.

20 Jesaitis, A.J., Naemura, J.R., Painter, R.G., Sklar, L.A. and Cochrane, C.G. (1982) Biochim. Biophys. Acta 719, 556-568.

21 Borregaard, N. and Tauber, A.I. (1984) J. Biol. Chem. 259, 47-52.

22 Steiner, J.P. and Bennett, V. (1988) J. Biol. Chem. 263, 1441714425.

23 Brown, A.E. and Elovson, J. (1980) Biochim. Biophys. Acta 597, 247-262.

24 Steck, T.L. and Kant, J.A. (1974) Methods Enzymol. 31, 172-180.

25 Bers, D.M. (1982) Am. J. Physiol. 242, C404-C408.

26 Morris, S.J., Gibson, C.C., Smith, P.D., Greif, P.C., Stirk, C.W., Bradley, D., Haynes, D.H. and Blumenthal, R. (1985) J. Biol. Chem. 260, 4122-4127.

27 Morrison, W.R. (1964) Anal. Biochem. 7, 218-224.

28 Ochs, D.L. and Reed, P.W. (1983) J. Biol. Chem. 258, 10116-10122.

29 Hoekstra, D., De Boer, T., Klappe, K. and Wilschut, J. (1984) Biochemistry 23, 5675-5681.

30 Hope, M.J., Walker, D.C. and Cullis, P.R. (1983) Biochem. Biophys. Res. Commun. 110, 15-22.

31 Struck, D.K., Hoekstra, D. and Pagano, R.E. (1981) Biochemistry 20, 4093-4099.

32 Düzgüneş, N., Allen, T.M., Fedor, J. and Papahadjopoulos, D. (1987) Biochemistry 26, 8435-8442.

33 Langer, G.A., Frank, J.S. and Nudd, L.M. (1979) Am. Physiol. Soc. 237, H239-H246.

34 Weiss, G.B. (1974) Annu. Rev. Pharmacol. 14, 343-354.

35 Barrowman, M.M., Cockcroft, S. and Gomperts, B.D. (1986) Nature 319, 504-507.

36 Mayorga, L.S., Diaz, R., Colombo, M.I. and Stahl, P.D. (1989) Cell Regul. 1, 113-124.
37 Gratzl, M., Dahl, G., Russell, J.T. and Thorn, N.A. (1977) Biochim. Biophys. Acta 470, 45-67.

38 Ekerdt, R., Dahl, G. and Gratzl, M. (1981) Biochim. Biophys. Acta 646, 10-22.

39 Gratzl, M. and Dahl, G. (1976) FEBS Lett. 62, 142-145.

40 Altstiel, L. and Branton, D. (1983) Cell 32, 921-929.

41 Woodman, P.G. and Warren, G. (1988) Eur. J. Biochem. 173, 101-108.

42 Gruenberg, J.E. and Howell, K.E. (1986) EMBO J. 5, 3091-3101.

43 Mayorga, L.S., Diaz, R. and Stahl, P.D. (1988) J. Biol. Chem. 263, 17213-17216.

44 Smolen, J.E., Stoehr, S.J., Traynor, A.E. and Sklar, L.A. (1987) J. Leuk. Biol. 41, 8-13.

45 Korchak, H.M., Rutherford, L.E. and Weissmann, G. (1984) J. Biol. Chem. 259, 4070-4075.

46 Slonczewski, J.L., Wilde, M.W. and Zigmond, S.H. (1985) J. Cell Biol. 101, 1191-1197.

47 Hong, K., Düzgüneş, N., Meers, P.R. and Papahadjopoulos, D. (1987) in Cell Fusion (Sowers, A.E., ed.), pp. 269-284, Plenum Press, New York.

48 Drust, D.S. and Creutz, C.E. (1988) Nature 331, 88-91.

49 Ali, S.M., Geisow, M.J. and Burgoyne, R.D. (1989) Nature 340, 313-315.

50 Mombers, C., Van Dijck, P.W.M., Van Deenen, L.L.M., De Gier, J. and Verkleij, A.J. (1977) Biochim. Biophys. Acta 470, 152-160.

51 Portis, A., Newton, C., Pangborn, W. and Papahadjopoulos, D. (1979) Biochemistry 18, 780-790.

52 Schrier, S.L., Junga, I. and Ma, L. (1986) J. Lab. Clin. Med. 108, 265-271.

53 Van Breemen, C. and De Weer, P. (1970) Nature 226, 760-761.

54 Bentz, J., Alford, D., Cohen, J. and Düzgüneş, N. (1988) Biophys. J. 53, 593-607.

55 Farooqui, S.M., Wali, R.K., Baker, R.F. and Kalra, V.K. (1987) Biochim. Biophys. Acta 904, 239-250.

56 Stamatatos, L., Leventis, R., Zuckermann, M.J. and Silvius, J.R. (1988) Biochemistry 27, 3917-3925.

57 Beckers, C.J.M. and Balch, W.E. (1989) J. Cell Biol. 108, 12451256.

58 Cockcroft, S. and Gomperts, B.D. (1985) Nature 314, 534-536.

59 Siegel, D.P., Banschbach, J., Alford, D., Ellens, H., Lis, L.J., Quinn, P.J., Yeagle, P.L. and Bentz, J. (1989) Biochemistry 28, 3703-3709.

60 Huttner, W.B., Schiebler, W., Greengard, P. and DeCamilli, P. (1983) J. Cell Biol. 96, 1374-1388.

61 Kosower, N.S., Glaser, T. and Kosower, E.M. (1983) Proc. Natl. Acad. Sci. USA 80, 7542-7546.

62 Arvinte, T., Hildenbrand, K., Wahl, P. and Nicolau, C. (1986) Proc. Natl. Acad. Sci. USA 83, 962-966.

63 Smith, R.J., Sam, L.M., Justen, J.M., Leach, K.L. and Epps, D.E. (1987) Br. J. Pharmac. 91, 641-649.

64 Comerford, J.G. and Dawson, A.P. (1989) Biochem. J. 829, 823829.

65 Meers, P., Bentz, J., Alford, D., Nir, S., Papahadjopoulos, D. and Hong, K. (1988) Biochemistry 27, 4430-4439. 